\title{
Biochemical markers of mineral bone disorder in South African patients on maintenance haemodialysis.
}

\author{
Waziri Bala, Duarte Raquel, Naicker Saraladevi
}

Department of Internal Medicine, Faculty of Health Sciences, University of the Witwatersrand, Johannesburg, South Africa.

\begin{abstract}
Background and objective: Despite the high mortality and morbidity associated with abnormalities in mineral and bone metabolism in haemodialysis patients, there is limited data on the pattern of mineral bone disorder in African CKD population. Therefore, the purpose of this study was to describe the pattern of mineral bone disease by evaluating biochemical parameters in patients on maintenance haemodialysis (MHD).

Methods: We evaluated the serum/plasma intact parathyroid hormone (iPTH), corrected calcium, phosphate, total alkaline phosphatase (TALP) and $25-\mathrm{OH}$ vitamin D levels of two hundred and seven patients undergoing MHD at two dialysis centers in Johannesburg.

Results: The MHD patients (133 men, 74 women) had a mean age of $54.5 \pm 15.6$ years with a median dialysis vintage of 24 months (IQR, 12-48) and a mean kt/V of $1.45 \pm 0.28$. The prevalence of hyperparathyroidism (iPTH $>150 \mathrm{pg} / \mathrm{ml})$, hyperphosphataemia, hypocalcaemia and $25-\mathrm{OH}$ vitamin D deficiency $(<30 \mathrm{ng} / \mathrm{ml})$ was $73.4 \%, 57.0 \%, 20.3 \%$ and $80.7 \%$ respectively. The combination of markers of bone turnover (iPTH $>150 \mathrm{pg} / \mathrm{ml}$ and TALP $>112 \mathrm{U} / \mathrm{L}$ ) suggestive of high turnover bone disease, was present in $47.3 \%$ of the study population. In multiple-logistic regression analysis, the odds ratio for developing hyperparathyroidism with hypocalcaemia and hyperphosphataemia were 5.32 (95\% CI 1.10 - 25.9, P = 0.03) and 3.06(95\% CI 1.15 - 8.10, $\mathrm{P}=0.02)$ respectively. Ninety eight $(47.3 \%)$ of the MHD patients had $\mathrm{PTH}$ within the recommended kidney disease improving global outcome (KDIGO) guidelines.

Conclusion: Secondary hyperparathyroidism and 25-OH vitamin D deficiency were common in our haemodialysis patients. Hypocalcaemia and hyperphosphataemia were strong predictors for developing secondary hyperparathyroidism.

Keywords: Biochemical markers, guidelines, mineral bone disorder, haemodialysis.

DOI: https://dx.doi.org/10.4314/ahs.v17i2.19

Cite as: Bala W, Raquel D, Saraladevi N. Biochemical markers of mineral bone disorder in South African patients on maintenance haemodialysis. Afri Health Sci. 2017;17(2): 445-452. bttps:/ / dx.doi.org/10.4314/abs.v17i2.19
\end{abstract}

\section{Introduction}

Chronic kidney disease-mineral bone disorder (CKD $\mathrm{MBD})$ is now defined as a systemic disorder of mineral and bone metabolism due to CKD manifested by either one or a combination of the following: (i) abnormalities of calcium, phosphorus, parathyroid hormone (PTH), or vitamin D metabolism; (ii) abnormalities in bone turn-

$$
\begin{aligned}
& \text { Corresponding author: } \\
& \text { Waziri Bala, } \\
& \text { Department of Internal Medicine, } \\
& \text { Faculty of Health Sciences, } \\
& \text { University of the Witwatersrand, } \\
& \text { Johannesburg, South Africa. } \\
& \text { Tel: +27848329071 } \\
& \text { Email: balawaziri@gmail.com }
\end{aligned}
$$

over, mineralization, volume, linear growth, or strength; or (iii) vascular or other soft tissue calcification and that the term renal osteodystrophy should exclusively be used to describe disorders in bone morphology associated with $\mathrm{CKD}^{1,2}$. Although bone biopsy is the gold standard for adequately describing the spectrum of CKD- MBD, it is less frequently utilized in clinical settings because of associated constraints. It is an invasive and cumbersome procedure that requires highly skilled personnel to interpret the obtained tissue samples. Therefore, clinicians largely depend on the biochemical parameters for monitoring and management of this important clinical entity that is associated with adverse clinical outcomes in CKD patients. In addition, the above aforementioned internationally acceptable definition has led to the ease of diagnosing $\mathrm{CKD} \mathrm{MBD}$ and allows valid comparison of studies in this field. 
In 2009, through extensive review of the literature the KDIGO (Kidney Disease Improving Global Outcomes) guideline work group came up with guidelines to assist clinicians in the management of patients with CKD$\mathrm{MBD}^{2}$. The guidelines were largely based on studies conducted on Asian, European and American populations. These guidelines were adopted by many African countries despite existence of racial differences in PTH, vitamin D and phosphorus as demonstrated by several studies $^{3-5}$. The lack of use of literature from Africa is likely due non-availability of robust data from these regions. Therefore, information obtained from this present study will add to the existing paucity of data on African patients with CKD-MBD.

\section{Materials and methods}

\section{Participants and study design}

This was a cross-sectional descriptive study involving two hundred and seven patients undergoing MHD (from June 2009 to April 2016) at two dialysis centers in Johannesburg, aged $\geq 18$ years with complete data for analysis. Exclusion criteria included patients with active malignancy, active liver disease, and patients on medications such as bisphosphonates or warfarin. Demographic and clinical data collected included age, gender, history of medications, underlying aetiology of CKD, duration of haemodialysis and blood pressure measurements. The research protocol was approved by the Health Research and Ethics committee (HREC) of the University of the Witwatersrand.

\section{Laboratory measurements}

Plasma intact PTH was measured by an electrochemiluminescence immunoassay (ECLIA) run on a Cobas 6000auto analyzer (Roche Diagnostics, Mannheim, Germany; reference range $10-65 \mathrm{pg} / \mathrm{ml}$ ).

Serum 25-OH vitamin D was measured by a chemiluminescent micro particle immunoassay (CMIA) technique (Abbott Laboratories, Abbott Park, Illinois, US). Reference ranges: $<10 \mathrm{ng} / \mathrm{ml}$ as severe deficiency, 10-29 ng/ $\mathrm{ml}$ as moderate deficiency, $30-100 \mathrm{ng} / \mathrm{ml}$ as sufficiency and $>100 \mathrm{ng} / \mathrm{ml}$ as toxic ${ }^{6}$.

Calcium, Phosphate and Alkaline phosphatase were measured using the ARCHITECT C8000 auto analyzer (Abbot Laboratories, Abbott Park, Illinois, US). Other biochemical parameters were determined using routine laboratory techniques.
Laboratory reference range for calcium and phosphate were as follows:

Calcium $(2.12-2.50 \mathrm{mmol} / \mathrm{l})$

Phosphate (0.79-1.45mmol/l).

Based on the above reference values and KDIGO recommendations the following definitions were employed in this study:

Hyperparathyroidism and hypoparathyroidism were defined as intact PTH $>150 \mathrm{pg} / \mathrm{ml}$ and PTH $<15 \mathrm{pg} / \mathrm{ml}$ respectively.

Hyperphosphataemia and hypophosphataemia were defined as phosphate levels $>1.45 \mathrm{mmol} / 1$ and $<0.80 \mathrm{mmol} / 1$ respectively.

Hypercalcaemia and hypocalcaemia were defined as calcium levels $>2.50 \mathrm{mmol} / 1$ and $<2.12 \mathrm{mmol} / 1$ respectively.

\section{Statistical analysis.}

Patients' demographic and baseline characteristics were presented as means and standard deviations (SD) or medians (Interquartile ranges) depending on the distribution of the variable, while categorical data was presented as proportions or percentages. The means of biochemical parameters were compared between diabetic and non-diabetic patients using an independent $\mathrm{t}$ - test and Pearson's or Fisher's exact test was utilized for proportion comparisons. Associations between $\log$ transformed PTH and other biochemical parameters were assessed by multiple linear regression analyses following significant associations obtained from univariate regression analyses. A logistic regression model was used to evaluate the effect of other biochemical parameters on the odds of developing hyperparathyroidism. A p-value of less than 0.05 was considered statistically significant at the $95 \%$ confidence interval. All analyses were performed using STATA version 12 (STATA Corp., TX, and USA).

\section{Results}

Two hundred and seven MHD patients (133 men, 74 women) were enrolled. Their mean age was $54.5 \pm 15.6$ years with a median dialysis vintage of 24 months (IQR, $12-48)$ and a mean Kt/V of $1.45 \pm 0.28$. Fifty six (27.1\%) of the study population were diabetic. Medications received included calcium carbonate 154 (74.4\%), Alfacalcidol 132 (63.8\%), Cholecalciferol 45(21.7\%) and 12(5.8\%) were on cinacalcet (Table 1). The majority of patients were on three times weekly $4 \mathrm{hr}$ sessions of haemodialysis. 
Table1. Study population characteristics.

\begin{tabular}{|c|c|}
\hline Parameters & Results \\
\hline Age(years) & $54.5 \pm 15.6$ \\
\hline \multicolumn{2}{|l|}{ Gender, n (\%) } \\
\hline Male & $133(64.23 \%)$ \\
\hline Female & $74(35.75 \%)$ \\
\hline Diabetes, n (\%) & $56(27.1 \%)$ \\
\hline \multicolumn{2}{|l|}{ Race, n (\%) } \\
\hline Black & $121(58.5 \%)$ \\
\hline Non Black & $86(41.5 \%)$ \\
\hline Creatinine $(\mu \mathrm{mmol} / \mathrm{l})$ & $695.48 \pm 278.61$ \\
\hline Calcium(mmol/l) & $2.28 \pm 0.22$ \\
\hline Phosphate(mmo/l) & $1.59 \pm 0.56$ \\
\hline Intact PTH(pg/ ml) & $451.85 \pm 430.38$ \\
\hline 25-OH vitamin D(ng/ml) & $21.16 \pm 10.71$ \\
\hline Haemoglobin(g/dl) & $10.26 \pm 2.0$ \\
\hline $\operatorname{Albumin}(g / L)$ & $31.91 \pm 6.12$ \\
\hline Systolic BP(mmhg) & $134.18 \pm 21.81$ \\
\hline Diastolic BP(mmhg) & $72.03 \pm 13.74$ \\
\hline Alkaline phosphatase(UI/L) & $143.21 \pm 115.26$ \\
\hline $\mathbf{K t} / \mathbf{V}$ & $1.45 \pm 0.28$ \\
\hline Dialysate Calcium (mmol/L) & $1.72 \pm 0.09$ \\
\hline Dialysis vintage(months) & $24(12-48)$ \\
\hline Calcium carbonate use $n(\%)$ & $154(74.4 \%)$ \\
\hline Cinacalcet n (\%) & $12(5.8 \%)$ \\
\hline Alfacalcidol n (\%) & $132(63.8 \%)$ \\
\hline Cholecalciferol n (\%) & $45(21.7 \%)$ \\
\hline
\end{tabular}

Continuous variables are presentedas mean \pm standard deviation and categorical data as frequencies (percentages). $\mathrm{BP}=\mathrm{blood}$ pressure

Table 2 shows a comparison of biochemical parameters and distribution of CKD-MBD abnormalities between diabetic $(n=56)$ and non-diabetic $(n=151)$ patients. Diabetic patients had significantly lower mean $25-\mathrm{OH}$ vitamin D as compared to non-diabetic patients. Other biochemical parameters were comparable between the groups.
The overall prevalence of hyperparathyroidism (>150pg/ $\mathrm{ml}$ ), hyperphosphataemia, hypocalcaemia and $25-\mathrm{OH}$ vitamin D deficiency $(<30 \mathrm{ng} / \mathrm{ml})$ was $73.4 \%, 57.0 \%, 20.3 \%$ and $80.7 \%$ respectively. The combination of markers of bone turnover $(>150 \mathrm{pg} / \mathrm{ml}$ and TALP $>112$ IU $/ \mathrm{L})$ suggestive of high turnover bone disease, was present in 47.3 $\%$ of the study population (Table 2 ). 
Table 2: Comparison of parameters/distribution of mineral bone disorder between diabetic and non-diabetic patients

\begin{tabular}{|c|c|c|c|c|}
\hline Variables & $\operatorname{ALL}(\mathrm{N}=207)$ & $\operatorname{DM}(n=56)$ & Non DM(n=151) & $\mathrm{P}$ \\
\hline Intact PTH & $451.85 \pm 430.38$ & $439.05 \pm 489.51$ & $454.70 \pm 413.05$ & 0.83 \\
\hline Corrected Calcium(mmol/l) & $2.28 \pm 0.22$ & $2.30 \pm 0.21$ & $2.275 \pm 0.22$ & 0.41 \\
\hline Phosphate(mmol/l) & $1.59 \pm 0.56$ & $1.52 \pm 0.51$ & $1.61 \pm 0.58$ & 0.25 \\
\hline Alkaline phosphatase(IU/L) & $143.21 \pm 115.26$ & $155.77 \pm 131.72$ & $139.15 \pm 109.41$ & 0.41 \\
\hline Hyperparathyroidism (>150 pg/ml) & $152(73.4 \%)$ & $38(67.9 \%)$ & $114(75.5 \%)$ & 0.84 \\
\hline Hypoparathyroidism $(<10 \mathrm{pg} / \mathrm{ml})$ & $2(9.7 \%)$ & $1(1.79 \%)$ & $1(6.6 \%)$ & 0.44 \\
\hline Hyperphosphataemia $(>1.45 \mathrm{mmol} / \mathrm{l})$ & $118(57.0 \%)$ & $27(48.2 \%)$ & $91(60.3 \%)$ & 0.19 \\
\hline Hypophosphataemia $(<0.80 \mathrm{mmol} / \mathrm{l})$ & $11(5.3 \%)$ & $4(7.1 \%)$ & $7(4.6 \%)$ & 0.44 \\
\hline Hypercalcaemia( $>2.50 \mathrm{mmol} / \mathrm{l})$ & $26(12.6 \%)$ & $8(14.3 \%)$ & $18(11.9 \%)$ & 0.53 \\
\hline Hypocalcaemia( $<2.12 \mathrm{mmol} / \mathrm{l})$ & $42(20.3 \%)$ & $10(17.9 \%)$ & $32(21.2 \%)$ & 0.91 \\
\hline $\operatorname{ALP}(>112 I U / L)$ & $103(49.8 \%)$ & $33(58.9 \%)$ & $70(46.4 \%)$ & 0.76 \\
\hline \multicolumn{5}{|l|}{ 25-Hydroxyvitamin $D(N=161)$} \\
\hline 25 OH vitamin D(ng/ml) & $21.16 \pm 10.71$ & $18.12 \pm 12.77$ & $22.21 \pm 9.82$ & 0.04 \\
\hline$(<30 \mathrm{ng} / \mathrm{ml})$ & $130(80.7 \%)$ & $35(92.1 \%)$ & $95(77.2 \%)$ & 0.04 \\
\hline$(<15 \mathrm{ng} / \mathrm{ml})$ & $47(29.2 \%)$ & $16(42.1 \%)$ & $31(25.2 \%)$ & 0.03 \\
\hline PTH $>150 \&$ TALP $>112$ & $98(47.3 \%)$ & $24(42.7 \%)$ & $74(49.0 \%)$ & 0.58 \\
\hline
\end{tabular}

Patients within KDIGO-recommended targets for calci- um, phosphate and PTH were 63.8\%, 37.7 \%, and 47.3\% respectively (Table 3).

Table 3. Distribution of patients achieving recommended guideline targets

\begin{tabular}{llll}
\hline Guidelines & Below target & Within target & Above target \\
\hline KDIGO & & & \\
PTH(2-9× upper normal range ) & $44(21.3 \%)$ & $98(47.3 \%)$ & $65(31.4 \%)$ \\
Calcium(within normal range) & $48(23.1)$ & $132(63.8 \%)$ & $27(13.0 \%)$ \\
Phosphate(within normal range) & $11(5.3 \%)$ & $78(37.7 \%)$ & $118(57.0 \%)$ \\
& & & \\
NKF KDOQI & & & \\
PTH(150-300 pg/ml) & $51(24.6 \%)$ & $54(26.1 \%)$ & $102(49.3 \%)$ \\
Corrected calcium(8.9-9.5 mg/d L) & $32(14.5 \%)$ & $112(54.1 \%)$ & $63(30.4 \%)$ \\
Phosphate(3.5-5.5mg/dl)) & $35(16.9 \%)$ & $104(50.2 \%)$ & $65(31.4 \%)$ \\
\hline
\end{tabular}

KDIGO, Kidney Disease Improving Global Outcomes; NKF KDOQI, National Kidney Foundation Kidney Disease Outcome Quality Initiative. 
In multiple logistic regression analysis, hypocalcaemia

and hyperphosphatasemia were identified as predictors of hyper-parathyroidism $(\mathrm{p}<0.05)$ (Table 4$)$.

Table 4. Logistic regression analysis for predictors of hyperparathyroidism.

\begin{tabular}{llll}
\hline Variables & Odds ratio & 95 CI & P-values \\
\hline Phosphate & 3.06 & $1.15-8.10$ & 0.024 \\
Calcium & 5.32 & $1.10-25.9$ & 0.03 \\
Alkaline phosphatise & 1.67 & $0.66-4.29$ & 0.28 \\
Diabetesmellitus & 0.60 & $0.19-1.84$ & 0.37 \\
Age & 0.76 & $0.25-2.33$ & 0.64 \\
25-hydroxyvitamin D & 0.39 & $0.10-1.60$ & 0.20 \\
\hline
\end{tabular}

$\mathrm{CI}$, confidence interval; covariates were by categories, Age $\geq 65$ years versus $<65$ years, phosphate $>1.45 \mathrm{mmol} / 1$ versus $\leq 1.45 \mathrm{mmol} / 1$, calcium $<2.12 \mathrm{mmol} / 1$ versus $\geq 2.12 \mathrm{mmol} / \mathrm{l}$, Alkaline phosphatase $>112 \mathrm{UI} / \mathrm{L}$ versus $\leq 112 \mathrm{UI} / \mathrm{L}, 25-\mathrm{OH}$ vitamin $\mathrm{D}<30 \mathrm{ng} / \mathrm{ml}$ versus $\geq 30 \mathrm{ng} / \mathrm{ml}$, Diabetes mellitus versus No diabetes.

Univariate linear regression revealed a significant association between log transformed PTH and phosphate $\left(\mathrm{r}^{2}=0.03, \mathrm{p}=0.007\right)$, calcium $\left(\mathrm{r}^{2}=0.02, \mathrm{p}=0.03\right)$, total alkaline phosphatase $\left(\mathrm{r}^{2}=0.05, \mathrm{p}=0.006\right), 25-\mathrm{OH}$ vitamin $\mathrm{D}$ $\left(\mathrm{r}^{2}=0.05, \mathrm{p}=0.005\right)$. When including all these parameters in a multiple regression analysis, only phosphate and 25$\mathrm{OH}$ vitamin $\mathrm{D}$ remained significantly correlated with log PTH; $p=0.02$ and 0.04 respectively.

\section{Discussion}

In agreement with previous studies from Africa and developed countries ${ }^{7-9}$, this study has revealed a high prevalence of derangements of biochemical markers of mineral bone disorder. Based on the cut-off values utilized by this study, hyperparathyroidism (PTH $>150)$ was present in $73.4 \%$ of the patients and $37 \%$ with a stricter cut-off value of $585 \mathrm{ng} / \mathrm{ml}$ (9 times the upper normal of our laboratory assay ). However, because of the dynamic nature and complexity of bone homeostasis, it is difficult to rely on one biochemical marker as a surrogate test of bone formation ${ }^{10}$. Therefore, utilizing both PTH and TALP, though not as specific as bone specific alkaline phosphatase, almost half of our study population were identified as having high bone turn over. In addition, the 2009 Kidney Disease Improving Global Outcomes (KDIGO) guidelines recommended measurement of TALP every 12 months in CKD 4-5D', and the additional cost in routinely utilizing bone specific alkaline phosphatase to monitor the management of CKD-MBD has not been justified.

Comparison of epidemiological data on prevalence of vitamin D deficiency is being hampered by lack of consensus on how to define this deficiency. However, the widely accepted definition includes serum $25(\mathrm{OH})$ vitamin D levels below $20 \mathrm{ng} / \mathrm{ml}$ while patients with $25(\mathrm{OH})$ vitamin D levels between 20 and $30 \mathrm{ng} / \mathrm{ml}$ are considered to be vitamin $\mathrm{D}$ insufficient ${ }^{6}$. One of the striking results of our study was the high prevalence $(80.7 \%, \mathrm{~N}=161)$ of inadequate vitamin $\mathrm{D}$ status in our study population and of which $29.2 \%$ were severely vitamin $\mathrm{D}$ deficient $(<15 \mathrm{ng} / \mathrm{m} /)$. These findings are consistent with previous cross-sectional studies in Americans ${ }^{11-13}$. In contrast to our finding regarding severe deficiency, Jabbar et $\mathrm{al}^{14}$ reported vitamin $\mathrm{D}$ deficiency $(<15 \mathrm{ng} / \mathrm{ml})$ in $90 \%$ of the patients and attributed it to the low vitamin $\mathrm{D}$ content in the traditional(vegetarian) Indian diet. Diabetic patients had significantly lower mean levels of $25-\mathrm{OH}$ vitamin D and inadequate vitamin D compared to non-diabetic patients. This finding is in line with previous studies from Europe and Asia ${ }^{15,16}$ in which a high prevalence of vitamin $\mathrm{D}$ deficiency was demonstrated in $>90 \%$ of the diabetic patients. This remarkably high prevalence could have been due to proteinuria, which is more common in diabetic nephropathy and is associated with heavy urinary loss of vitamin $\mathrm{D}$ binding protein, as proposed by previous studies ${ }^{16,17}$. However, in general, factors that could 
account for vitamin $\mathrm{D}$ deficiency in patients with CKD include reduced dietary intake, loss of vitamin D binding protein in urine and increased levels of FGF 23 in $\mathrm{CKD}^{16}$.

In an attempt to reduce the adverse clinical outcomes associated with CKD-MBD several guidelines were proposed by various regional and global bodies ${ }^{2,18,19}$. Based on the recommended target ranges by the widely adopted KDIGO guidelines ${ }^{2}$, more than half of our study population had serum phosphate levels above the target level (Phosphate $>1.45 \mathrm{mmol} / \mathrm{L}$ ). This is similar to other large observational multicenter studies[Dialysis outcomes and practice patterns (DOPPS I) ${ }^{20}$ and a study from Italy $^{21}$ that both reported serum phosphate of $>5.5 \mathrm{mg} /$ $\mathrm{dl}(1.78 \mathrm{mmol} / \mathrm{L})$ in $51.6 \%$ of the patients. Despite the advances in haemodialysis, with the invention of more effective dialysis membranes and the use of ultrapure dialysate, the removal of phosphate is still inadequate. The conventional HD (3 times per week, $4 \mathrm{~h}$ session) removes approximately 2.3-2.6g/week compared to 4.5-4.9g by the nocturnal HD ( 8 hrs/day) 22 . The majority of our patients are on conventional HD with a very few of them $(9.2 \%)$ on nocturnal dialysis. Therefore, one of the reasons that could have accounted for the high prevalence of hyperphosphataemia is the ineffective removal of phosphate by conventional haemodialysis. In addition, calcium carbonate which is used as phosphate binder in most of our patients has lower phosphate binding capacity compared to non-calcium based phosphate binders. Other notable patient factors are the adherence to both medications and dietary restriction.

In this study, according to the KDIGO recommendation that PTH should be maintained between 2-9 times the upper limit of normal range (i.e. $130-585 \mathrm{pg} / \mathrm{ml}$ ), the proportion of patients within the target guideline level was higher than that reported by previous studies ${ }^{7,20,23}$. Their reported lower values were likely due to utilization of KDOQI guidelines with narrower recommended ranges of PTH (150-300pg/ml).

Interestingly, a significant percentage of our patients had their corrected calcium within the KDIGO recommended guidelines which is higher than the report from DOPPS II $42.5 \% 20$. Re analyzing our data based on KDOQI the number still remains slightly higher (54.1\%). Overall, the discrepancy between the current study and other previous studies may likely be due to differences in the use of phosphate binders, dialysate calcium concentration and dietary phosphate intake.

In keeping with previous studies ${ }^{24}$, logistic regression analysis revealed hypocalcaemia and hyperphosphateamia as predictors of hyperparathyroidism. This further supports the classical role of hyperphospataemia and hypocalcaemia in the pathogenesis of CKD-MBD. In addition, we found phosphataemia to have remained closely related to log-transformed PTH in multivariate linear regression. The strength of our study is the larger sample size compared to other previous studies from Africa ${ }^{7,9,25}$.

\section{Limitations of our study include:}

Firstly, the lack of bone biopsy to definitively describe the patterns of MBD in our patients. However, studies have shown a good association between biochemical markers and histological findings ${ }^{26,27}$. Secondly, this was a cross -sectional study so we could not establish a temporal relationship between the biochemical markers and phosphate binders. Thus there is a need for a longitudinal study to assess this relationship. Nonetheless, findings from this study have provided us with important insights on the spectrum of CKD-MBD in African MHD patients.

\section{Conclusion}

Abnormalities of biochemical markers of mineral bone disorder were common in our MHD patients and moderately large proportion of the patients were outside the KDIGO recommended target levels. However, due to the existence of racial differences in PTH, vitamin D and phosphorus levels it is unclear whether these guidelines could be extrapolated to African MHD patients. Therefore, there is a need for large multicenter studies in Africa to support management of CKD-MBD in African patients with CKD.

\section{Conflict of interest}

The authors declare they have no conflict of interest.

\section{References}

1. Moe S, Drueke T, Cunningham J, Goodman W, Martin $\mathrm{K}$, Olgaard K, et al. Definition, evaluation, and classification of renal osteodystrophy: A position statement from Kidney Disease: Improving Global Outcomes (KDIGO). Kidney Int. 2006;69(11):1945-53.

2. Kidney Disease: Improving Global Outcomes (KDIGO) CKD-MBD Work Group. KDIGO clinical practice 
guideline for the diagnosis, evaluation, prevention, and treatment of chronic kidney disease-mineral and bone disorder (CKD-MBD). Kidney Int Suppl. 2009;76(113): S1-130. Pubmed

3. Gutierrez OM, Farwell WR, Kermah D, Taylor EN. Racial differences in the relationship between vitamin $\mathrm{D}$, bone mineral density, and parathyroid hormone in the National Health and Nutrition Examination Survey. Osteoporos Int. 2011;22(6):1745 -53. Pubmed

4. Malluche HH, Mawad HW, Monier-Faugere MC. Renal osteodystrophy in the first decade of the new millennium: analysis of 630 bone biopsies in black and white patients. J Bone Miner Res. 2011;26(6):1368 -76. Pubmed 5. Gupta A, Kallenbach LR, Zasuwa G, Divine GW. Race is a major determinant of secondary hyperparathyroidism in uremic patients. J Am Soc Nephrol. 2000;11(2):330 -4. Pubmed

6. Nigwekarsu, Tamez H, Thadhani RI. Vitamin D and chronic kidney disease-mineral bone disease (CKDMBD). Bonekey reports. 2014;3:498.

7. Buargub MA, Nabulsi MF, Shafeh TA. Prevalence and pattern of renal osteodystrophy in chronic hemodialysis patients: a cross sectional study of 103 patients. Saudi J Kidney Dis Transpl. 2006;17(3):401-7.

8. Levin A, Bakris GL, Molitch M, Smulders M, Tian J, Williams LA, et al. Prevalence of abnormal serum vitamin D, PTH, calcium, and phosphorus in patients with chronic kidney disease: results of the study to evaluate early kidney disease. Kidney Int. 2007;71(1):31-8. Pubmed 9. Seck SM, Dahaba M, Ka EF, Cisse MM, Gueye S, Tal AOL. Mineral and Bone Disease in Black African Hemodialysis Patients: A Report From Senegal. Nephro-urology Monthly. 2012;4(4):613-6. Pubmed

10. Moorthi RN, Moe SM. Recent advances in the noninvasive diagnosis of renal osteodystrophy. Kidney Int. 2013;84(5):886-94. Pubmed

11. Porter A, Gilmartin C, Srisakul U, Arruda J, Akkina S. Prevalence of $25-\mathrm{OH}$ vitamin D deficiency in a population of hemodialysis patients and efficacy of an oral ergocalciferol supplementation regimen. Am J Nephrol. 2013;37(6):568-74. Pubmed

12. Gonzalez EA, Sachdeva A, Oliver DA, Martin KJ. Vitamin $\mathrm{D}$ insufficiency and deficiency in chronic kidney disease. A single center observational study. Am J Nephrol. 2004;24(5):503-10.

13. Wolf M, Shah A, Gutierrez O, Ankers E, Monroy M, Tamez H, et al. Vitamin D levels and early mortal- ity among incident hemodialysis patients. Kidney Int. 2007;72(8):1004-13. Pubmed

14. Jabbar Z, Aggarwal PK, Chandel N, Khandelwal N, Kohli HS, Sakhuja V, et al. Noninvasive assessment of bone health in Indian patients with chronic kidney disease. Indian J Nephrol. 2013;23(3):161-7. Pubmed

15. Peng Y, Li LJ. Serum 25-hydroxyvitamin D level and diabetic nephropathy in patients with type 2 diabetes mellitus. International Urology and Nephrology. 2015;47(6):983-9. 16. Fernandez-Juarez G, Luno J, Barrio V, de Vinuesa SG, Praga M, Goicoechea M, et al. $25(\mathrm{OH})$ vitamin D levels and renal disease progression in patients with type 2 diabetic nephropathy and blockade of the renin-angiotensin system. Clin J Am Soc Nephrol. 2013;8(11):1870-6.

17. De Boer IH, Ioannou GN, Kestenbaum B, Brunzell JD, Weiss NS. 25-Hydroxyvitamin D levels and albuminuria in the Third National Health and Nutrition Examination Survey (NHANES III). Am J Kidney Dis. 2007;50(1):69-77. Pubmed

18. K/DOQI clinical practice guidelines for bone metabolism and disease in chronic kidney disease. Am J Kidney Dis. 2003;42(4 Suppl 3):S1-201. Pubmed

19. Clinical practice guideline for the management of secondary hyperparathyroidism in chronic dialysis patients. Therapeutic apheresis and dialysis : official peer-reviewed journal of the International Society for Apheresis, the Japanese Society for Apheresis, the Japanese Society for Dialysis Therapy. 2008;12(6):514-25.

20. Young EW, Akiba T, Albert JM, mccarthy JT, Kerr PG, Mendelssohn DC, et al. Magnitude and impact of abnormal mineral metabolism in hemodialysis patients in the Dialysis Outcomes and Practice Patterns Study (DOPPS). Am J Kidney Dis. 2004;44(5 Suppl 2):34-8. Pubmed

21. Gallieni M, Cucciniello E, D'Amaro E, Fatuzzo P, Gaggiotti A, Maringhini S, et al. Calcium, phosphate, and PTH levels in the hemodialysis population: a multicenter study. J Nephrol. 2002;15(2):165-70. Pubmed

22. Cupisti A, Gallieni M, Rizzo MA, Caria S, Meola M, Bolasco P. Phosphate control in dialysis. International Journal of Nephrology and Renovascular Disease. 2013;6:193-205.

23. Kim G-H, Choi BS, Cha DR, Chee DH, Hwang E, Kim HW, et al. Serum calcium and phosphorus levels in patients undergoing maintenance hemodialysis: A multicentre study in Korea. Kidney Research and Clinical Practice. 2014;33(1):52-7.

24. Ghosh B, Brojen T, Banerjee S, Singh N, Singh S, 
Sharma OP, et al. The high prevalence of chronic kidney disease-mineral bone disorders: A hospital-based cross-sectional study. Indian J Nephrol. 2012;22(4):285-91. Pubmed

25. Sanusi AA, Arogundade FA, Oladigbo M, Ogini LM, Akinsola A. Prevalence and pattern ofrenal bone disease in end stage renal disease patients in Ile-Ife, Nigeria. West African Journal of Medicine. 2010;29(2):75-80.

26. Wang M, Hercz G, Sherrard DJ, Maloney NA, Segre
GV, Pei Y. Relationship between intact 1-84 parathyroid hormone and bone histomorphometric parameters in dialysis patients without aluminum toxicity. AmJ Kidney Dis. 1995;26(5):836-44. Pubmed

27. Torres A, Lorenzo V, Hernandez D, Rodriguez JC, Concepcion MT, Rodriguez AP, et al. Bone disease in predialysis, hemodialysis, and CAPD patients: evidence of a better bone response to PTH. Kidney Int. 1995;47(5):1434 -42. Pubmed 